\title{
BRIEF REPORT: THE ROLE OF PSYCHOLOGICAL LANGUAGE IN CHILDREN'S THEORY OF MIND AND SELF-CONCEPT DEVELOPMENT
}

\begin{abstract}
Children's self-concept and theory of mind are both important factors in children's social, cognitive and emotional development. Research on gender differences in children's theory of mind understanding reveals contradictory findings such as higher degree of social understanding or theory of mind in girls (Villaneuva Badenes, Clemente Estevan, \& Garcia Bacete 2000), boys score higher than girls (Russell et al., 2007), or no gender differences at all (Villaneuva Badenes, Clemente Estevan, \& Garcia Bacete, 2000). This research study is part of a larger 3-year longitudinal study, investigating children's social and emotional development during middle childhood. This study explores the gendered relations between self-concept and social understanding (including psychological language) in middle school aged children ( $n=49$, ages 11-13). Results suggest a negative correlation between boys' sense of self-worth and psychological language. Implications for curriculum development that promotes socio-emotional literacy within middle school are discussed.
\end{abstract}

Key words: Theory of Mind, self-concept, social-cognition, middle childhood

How children think and feel about themselves plays an important role in their learning and social interactions in the classroom. Social experiences of children during middle childhood signify the developmental commencement of schooling experiences, which include children's interactions with their teachers, peers and others (Harter, 1999). This developmental period also provides an opportunity for children to continue to develop their sense of self as they form relationships with peers, parents, teachers and significant others (Bruner, 1996).

Address for correspondence: Sandra L. Bosacki, Faculty of Education, Brock University, 500 Glenridge Ave., St. Catharines, ON L2S 3A1, Canada. E-mail: sandra.bosacki@brocku.ca 
Many theorists state that talking with others about the social, emotion and psychological world around them, children can initiate reflection on or start thinking about other peoples' activities in psychological terms (Chapman, 1991; Piaget, 1945/1962; Vygotsky, 1934/1986; de Rosnay \& Hughes, 2006; Lu, Su, \& Wang, 2008; Symons, 2004; Taumoepeau \& Ruffman, 2008).

Conversations with older siblings, peers or adults provide significant sources of information about the social world, and allow children an opportunity to internalize or develop mental representations of these conversations into their own thoughts about the social world (Rieber \& Carlton, 1987 - see also research by Ted Ruffman: Taumoepeau \& Ruffman, 2006, 2008; Ruffman et al., 2006; Slade \& Ruffman, 2005). Harris (1999) indicates that a coherent dialogue between parents and children about emotional states can potentially predict a more accurate understanding of emotion for both girls and boys. Harris (1999) claims that such mental state and emotion talk are essential to the development of mental states and feelings, which are essential features of the human social world. Children learn to internalize the rules of language and dialogue, both of which are influential on children's internal speech (Bruner, 1986).

Further research by Denham et al. (1994) suggests that emotional understanding develops in familial contexts where emotions and their consequences are explained by parents or caregivers. Moreover, this internalization is also responsible for gender roles of children (Bussey \& Bandura, 1999), which is a significant process in their development. According to social cognitive theorists, children internalize representations of self and other through discourses about mental states with parents and others (Meins, 1997).

Such mental reasoning includes understanding mental states in self and other in relation to others' behaviour. Also known as Theory of Mind (ToM) understanding or social understanding (Astington, 2003; Wellman, 1990; etc.), this metacognitive ability also includes the awareness and understanding of self and others thoughts and feelings as well as one's self concept (Lalonde \& Chandler, 1995; Slomkowski \& Dunn, 1996). The ability to correlate feelings of self worth with others' understandings of how we should expect to feel in different situations is an important developmental process, as it allows individuals to ultimately decide how to respond to different situations (Lalonde \& Chandler, 1995; Slomkowski \& Dunn, 1996).

In early childhood, the ability to recognize, represent and understand others thoughts and emotions provides the social-cognitive foundation for the later development of socio-emotional competency (Lalonde \& Chandler, 1995; Slomkowski \& Dunn, 1996). In particular, peer influence provides a psychological and social base for children's development of various knowledge, language, and possibly, their ToM (Villaneuva Badenes, Clemente Estevan, \& Garcia Bacete, 2000). Furthermore, other research studies have found that children's use of psychological language in conversation with peers to be correlated with 
their performance on ToM measures (False Belief; Brown, Donelan-McCall, \& Dunn, 1996).

Similarly, other research by Lewis, Freeman, Kyriakidou, Maridaki-Kassotaki and Berridge (1996) found that the number of adult family members, the number of older siblings, and overall interactions with older children has a positive influence on children's ToM scores. Encouraging mental state talk in children aides in facilitating the development of ToM in children (Dunn et al., 1991; Ruffman et al., 2002; Symons et al., 2006). Within the familial context, when talking about mental and feeling states is encouraged in childrearing practices, there develops a further association with a greater ToM understanding in children (Dunn et al., 1991; Guajardo \& Watson, 2002; Hughes \& Dunn, 1998; Ruffman et al., 2002; Symons et al., 2005). Other studies too have found correlations between language and social understanding (e.g. Cutting \& Dunn, 1999; de Villers, 2000; Happé, 1995; Jenkins \& Astington, 1996).

In relation to mental representation during social dialogue, conversations also help children to develop a sense of self in relation to others (e.g., Bakhtin, etc.). Self -concept is the ability to judge our competencies in various contexts, and also how we describe and justify our perceived self worth as a person. According to Harter (1985) one method of assessing children's perceptions of their self-concepts is by the Self Perception Profile for Children (SPPC). Much like self-concept, "self-esteem" is also used interchangeably to determine how much one likes oneself as a person (Harter, 1996).

Past research suggests that connections may exist between children's ability to understand higher order or interpretative ToM, and their perceptions of their self-concept (Bosacki, 2008; Cahill et al, 2007; Taumoepeau \& Ruffman, 2006). Although the majority of research supports a positive link between psychological and emotional understanding and self-concept (Selman, 1980; Trudeau \& Reich, 1995), some investigators claim that the later correlates of ToM with self and emotion understanding may not be uniformly positive (Bosacki, 2003, 2007; Burton \& Mitchell, 2003; Dunn, 2005, 2008; Harkness et al., 2005, 2010).

Given this association, in the present study, we predict that children who report a positive self-concept may also have a more sophisticated understanding of how others think and feel, or a more advanced theory of mind. Therefore, this research study investigates the possible relations between children's selfperceptions and advanced ToM understanding in socially ambiguous situations.

Research on the role gender plays in children's ToM understanding reveals contradictory findings with some studies finding no gender differences in ToM ability (Villaneuva Badenes, Clemente Estevan, \& Garcia Bacete, 2000), whereas some suggest girls score higher than boys (Maccoby, 1990; Villaneuva Badenes, Clemente Estevan, \& Garcia Bacete, 2000). For example, Saarni (1984) and Brown and Dunn (1996) employed White Lie tasks to explore gender differences on an emotional understanding task and a White Lie task. Subsequent research by Vil- 
laneuva Badenes, Clemente Estevan, and Garcia Bacete (2000) partially confirms these findings. They found that girls perform better than boys on the White Lie and Deception task.

However, these researchers indicated that they were unable to conclusively confirm that girls score higher than boys on the emotional task. These limitations, according to the researchers, could potentially be based on the limited difficulty of task demands or "ceiling effect which creates a maximum level score potential that participants can achieve in a task. These researchers suggest that a contradictory or secondary emotions understanding task may be more appropriate for children (Villaneuva Badenes, Clemente Estevan, \& Garcia Bacete, 2000). Although our research study does not directly address emotional understanding, we assessed children's mental state vocabulary to explore ToM and self-perceptions in both girls and boys.

Carpendale and Lewis (2004) suggest that language can be used as a window for children to reveal their social understanding. Language, according to the same researcher, "mediates children's knowledge of reality-children learn the criteria for words to talk about human activity and then can reflect on the psychological world" (Carpendale \& Lewis, 2004, p. 89). Therefore, language, also described by any other form of communicative interaction, is the way in which children learn about the experiences of others, and thus are able to develop "a more complete set of criteria" (Carpendale \& Lewis, 2004, p. 89).

Social understanding (the way in which children understand the social world around them; Carpendale \& Lewis, 2006) and mental state language (a facilitating factor for ToM; Lu, Su, \& Wang, 2008), is often divided into two types of talk that refers to cognitive states and emotional states. The cognitive state is a reference to beliefs and others' mental events, and usually includes words such as; "think, know, believe, wonder, remember, forget, guess, pretend, understand and expect". Cognitive state words include references to mental life in relation to "mind, imagination, intellect or metacognition" (Symons, 2004). Emotional states are direct feelings such as primary or secondary emotions such as happy and sad. Emotional states can also be indirect words such as hurt, excited or glad. In the present study, to answer our research questions we explored how self-concept and ToM are related, and if there exist any gender differences in grade 6 and 7 children $(n=49)$.

The assumption that a higher self concept will lead to a more advanced understanding of ToM predicts that children with a more positive sense of self will provide more complex explanations of how others think and feel as expressed in their story interview responses. Thus we predicted that results from this study would demonstrate a positive correlation between ToM (as defined by the use of psychological vocabulary in response to the socially ambiguous story interview) and self-concept scores. Thus, if the total word count of psychological vocabulary (e.g., cognitive and emotion words such as happy, proud, 
and embarrassed) is correlated to a higher self-concept score, this suggests a significant relation between the self and social understanding.

\section{Methods}

\section{Procedures}

Bruner (1996) describes the school as a complex, social institution wherein the ability of children to make sense out of social information plays a vital role in self development and subsequent social relations. The school is therefore a data rich environment for research on children's psychological development and behavior.

As part of a larger longitudinal study of children's social, emotional and cognitive development and understanding (Bosacki, 2008), the present study consisted of 49 grades $6 / 7$, school-aged girls $(n=30)$ and boys $(n=19)$ from a mainly $(90 \%)$ Euro-Canadian, English-speaking, middle SES, semi-rural neighbourhood. Less thank $10 \%$ of the participants reported speaking English as their second language at home. During school visits the researcher had children complete various self-report questionnaires, and participate in individual interviews including responding to short-story interviews. This mixed-method study employed both qualitative and quantitative research methods, these interviews were audio-taped for subsequent transcription and analysis.

\section{Data sources}

Perceived self-concept

Using an adapted score from Harter's (1985) SPCC, Harter's (1999) adapted version of SPCC was administered to assess perceived self-concept. This scale measured children's self-perceptions in three areas: physical appearance, behavioural conduct and global self worth. The latter sub scale was used to determine children's overall feelings of whether or not they were happy with themselves (e.g., "How happy are you with being yourself?"). Children were asked to rate themselves on questions involving whether or not they thought they were good looking (physical appearance, "How happy are you are with the way that you look?"), and whether or not they thought their behaviour was well behaved (behavioural conduct, "How well behaved do you think you are?"). Responses were scored from 1 (not at all like me) to 4 (a lot like me), with high scores indicating positive self-perceptions.

\section{Theory of mind understanding}

Using a short story interview (Social Ambiguous Stories, SAS, see Bosacki, 1998, 2008), which described ambiguous social situations within different contexts (playground and soccer field), children were then questioned to assess their ToM 
understanding. The responses were then coded to create a social understanding score as represented by the number of mental state words. Simple and complex emotional words such as "hate", "shy", and "embarrassed" were coded to create an overall emotional score. To calculate the proportion of psychological language or mental state terms within the contact of overall words spoken the total the total mental state (cognitive words such as belief, think, wonder, etc.) words were divided by the total words spoken during the interview. The number was then multiplied by a hundred to achieve a total percentage. The total word count of words spoke during the interview was calculated for a measure of expressive vocabulary. The higher the proportionate percentage of mental state terms or psychological language, the more sophisticated the child's understanding of ToM understanding.

\section{Data analysis}

Once the total psychological language scores were tabulated from transcripts, data was analyzed using SPSS software. Variables measuring self-concept and psychological language (emotional and cognitive) were compared across gender to see if any gender differences exist.

\section{Results}

Mean percentage scores of psychological language were calculated for the total sample and girls and boys separately. Results revealed overall, the mean complex vocabulary percentage score for boys and girls was $23.40 \%$ (with a standard deviation of 10.43). For boys only, this was slightly higher at $25.39 \%$ $(S D=10.33)$, while for girls, this score was slightly lower than the average, $22.13 \%$ $(S D=10.53)$. The mean global self worth score for boys and girls was 19.06, with $S D$ of 3.47. For boys only, the global self worth score was lower than the overall average, $18.63(S D=3.32)$. For girls, the mean global self worth score was slightly higher at $19.33(S D=3.60)$.

Correlation analysis revealed no significant correlations between the psychological language percentage scores and global self worth score. For the sample size we used $(n=49)$, there was no relation between a higher global self worth score and psychological language as determined by the use of emotional/cognitive words. In other word, psychological language or a better understanding of ToM is not correlated to global self worth, or vice versa.

Although, the correlation between global self worth and psychological language (emotional/cognitive words) was not significant, we tested to see if there were any relations at all between the Psychological language percentage and other SPPC subscales, such as the physical appearance score.

Results show the mean physical appearance for boys and girls was $18.89 \%$ with $S D=3.35$. Girls' mean physical appearance score was slightly higher, (18.93; $S D=4.29)$, than boys $(18.84 ; S D=3.41)$. When correlated with psychological 
language percentages, the correlation between combined boys and girls was not significant $(r=0.173)$, as was the relation between girls' physical appearance and their complex percentage $(r=-0.017)$ However, unexpectedly, there was a significant negative correlation $(-0.504, p<0.05)$ between boys' perceptions of their physical appearance and the psychological language percentage suggesting that the higher their score on physical self-concept the lower they scored on their use of psychological vocabulary and vice versa.

\section{Discussion}

In general, the main purpose of this study was to explore the gendered relations between children's self-concepts and their ToM understanding (as defined by the use of psychological language) in the middle school grades. However, while we did not find a significant relation between a child's global self worth and their ToM understanding, our findings suggest that there was a gender-related difference in how boys and girls perceived themselves in relation to their ToM. While we looked at overall scores for psychological language, results did not indicate any gender differences in the overall use of psychological language. Findings in general do not support research on gender stereotypic behaviour that suggests that girls may refer to a greater number of psychological terms (e.g., cognitive and emotion words) and thus reflect a higher social understanding (Maccoby, 1990; Villaneuva Badenes, Clemente Estevan, \& Garcia Bacete, 2000).

One of the suggestions which can attribute for the significant negative relation between boys' physical appearance and their use of psychological language is that boys with a relatively high or positive sense of physical self may be less likely to use psychological language to make sense of their own and other's actions. A possible explanation could be that perhaps boys who use a higher amount of psychological language may be more likely to spend more time involved with solitary activities such as reading, computer activities, drawing, playing video games, or watching television. More time reading can also attribute to the more comprehensive and diverse psychological language scores indicated by the boys. Additionally, these boys may also spend more time with their parents, as opposed to with peers. More time communicating with their parents can potentially lead to more complex psychological language being used. This can also lead to more time learning how to effectively communicate with their parents about their feelings and emotions in a comfortable zone. Parents may also encourage their children to use psychological language in social settings rather than rely on physical features to gain status. For example, parents should encourage their children to gain social acceptance by using their cognitive abilities (e.g. being social, networking) than rely on using their physical appearance to gain social status. 
Interestingly, the finding that suggests a significant relation exists between boys' more negative sense of physical appearance with a greater use of psychological language supports past research suggesting that boys not only report higher levels of physical appearance dissatisfaction than some girls, but they also report dieting as a specific solution to reach their desires to be bigger or more muscular (Furham \& Calnan, 1998; Riccairdelli \& McCabe, 2007). For example, a survey conducted by the McCreary Centre Society (2004) found that $43 \%$ of boys were not satisfied with their appearance; $19 \%$ of healthy weight boys thought they were underweight, and another $6 \%$ of boys thought they were overweight. From this study we can see that boys are internalizing social messages which they are receiving about the way in which society expects boys physical appearance to be with how they feel the world sees them. Their understanding of what others such as their parents and peers expect of them is manifest through their dissatisfaction with their physical appearance and their desire to change their perception of self. Such findings illustrate the importance of dedicating more research to exploring boys' perceptions of their physical sense of self and appearance.

More research needs to investigate why a negative self-perceived physical appearance is related to higher use of psychological terms for boys. This area needs to be explored further as it is missing from existing data. However this research is unique as it contributes to the little existing literature on theory of mind and self concept as it identifies differences in gender (boys) and theory of mind.

A limitation to this study is the sample size $(n=49)$ which is considerably small and lacking in cultural diversity. For example, although less than $10 \%$ of the participants reported speaking a language other than English as their home language. This small percentage of children may have affected the results as language spoken within the family may play a role in the development of Theory of Mind (Cutting \& Dunn, 1999), as well as self-concept (Harter, 1996). A larger, more culturally diverse sample size could have expanded anticipated results as a larger sample size may have detected more significant correlations between self worth, physical appearance and psychological language, as well as any gender differences.

Additionally, the measurements capturing psychological language may not be particularly conducive to measuring a child's cognitive and emotional vocabulary. The interviews and specific questions asked were not specifically formulated to encourage children to use cognitive and emotional vocabulary.

\section{Future research}

Future research studies should employ more specific measurements (interview questions, assessments, etc.) that can better engage children to use more comprehensive emotional and cognitive vocabulary. 
This research makes two significant contributions to the current discourse on the nature of social cognition in middle childhood. Theoretically, it highlights the complex connections among children's perceptions of self-worth and their ability to understand mental states and emotions. Practically, it provides empirical groundwork for curriculum development in affective education aimed to promote socio-emotional literacy within middle school. Research findings also point to the importance of engaging children in creating positive self worth and physical appearance. In a study by de Rosney and Hughes (2006), they found that children's engagement in conversational interactions had a positive influence on their socio-cognitive understanding (de Rosney \& Hughes, 2006, p. 32). Thus, the results of this study suggest that parents and teachers should continuously engage their children in a range of conversational activities to strengthen their socio-cognitive and emotional understanding, including the promotion of a positive sense of self - especially for both girls and boys. Future research needs to explore concrete relations between ToM and self-concept, as well as any significant gender differences. Future research also needs to evaluate the role of the language spoken with family members (parents, siblings) in children's Theory of Mind and self-concept.

\section{References}

Bosacki, S. (2008). Children's Emotional Lives: Sensitive Shadows in the Classroom. New York: Peter Lang.

Bosacki, S. (1998). Theory of Mind in Preadolescence: Connections Among Social Understanding, Self-Concept, and Social Relations. Doctoral dissertation. University of Toronto, Toronto, Canada.

Brown, J.R. \& Dunn, J. (1996). Continuities in emotion understanding from three to six years. Child Development, 67 (3), 789-802.

Brown, J.R., Donelan-McCall, N., \& Dunn, J. (1996). Why talk about mental states? The significance of children's conversations with friends, siblings, and mothers. Child Development, 67 (3), 836-884.

Bruner, J. (1996). The Culture of Education. Cambridge, MA: Harvard University Press.

Bussey, K. \& Bandura, A. (2004). Social cognitive theory of gender development and functioning. In A. Eagly, A. Beall, \& R. Sternberg (Eds.), The Psychology of Gender (pp. 92-119). New York: Guilford.

Cahill, K., Deater-Deckard, K., Pike, A., Hughes, C. (2007). Theory of mind, selfworth and the mother-child relationship. Social Development, 16 (1), 45-56.

Carpendale, J.M. \& Lewis, C. (2004). Constructing an understanding of mind: The development of children's social understanding within social interaction. Behavioral and Brain Sciences, 27 (1), 79-96.

Chapman, M. (1991). The epistemic triangle: Operative and communicative components of cognitive development. In M. Chandler \& M. Chapman (Eds.), Cri- 
teria for Competence: Controversies in the Conceptualization and Assessment of Children's Abilities (pp. 209-228). Hillsdale, NJ: Lawrence Erlbaum Associates. Cutting, A.L. \& Dunn, J. (1999). Theory of mind, emotion understanding, language, and family background: Individual differences and interrelations. Child Development, 70 (4), 853-865.

Denham, S.A., Zoller, D., \& Couchard, E.A. (1994). Socialisation of preschoolers' emotion understanding. Developmental Psychology, 30 (6), 928-936.

de Rosnay, M. \& Hughes, C. (2006). Conversation and theory of mind: Do children talk their way to sociocognitive understanding? British fournal of Development Psychology, 24 (1), 7-37.

de Villiers, J. (2000). Language and theory of mind: What are the developmental relationships? In S. Baron-Cohen, H. Tager-Flusberg, \& D.J. Cohen (Eds.), Understanding Other Minds: Perspectives from Developmental Cognitive Neuroscience (pp. 83-123). Oxford: Oxford University Press.

Dunn, J., Brown, J., \& Beardsall, L. (1991). Family talk about feeling states and children's later understanding of others' emotions. Developmental Psychology, 27 (3), 448-455.

Furnham, A. \& Calnan, A. (1998). Eating disturbance, self-esteem, reasons for exercising and body weight dissatisfaction in adolescent males. European Eating Disorders Review, 6 (1), 58-72.

Guajardo, N.R. \& Watson, A.C. (2002). Narrative discourse and theory of mind development. Fournal of Genetic Psychology, 163 (3), 305-325.

Happé, F.G.E. (1995). The role of age and verbal ability in the theory of mind task performance of subjects with autism. Child Development, 66 (3), 843-855.

Harris, P.L. (1999) Acquiring the art of conversation. In M. Bennett (Ed.), Developmental Psychology: Achievements and Prospects (pp. 89-105). Hove: Psychology Press.

Harter, S. (1985). Manual for the Self-Perception Profile for Children (SPPC). Denver: University of Denver.

Harter, S. (1996). Teacher and classmate influences on scholastic motivation, selfesteem, and level of voice in adolescents. In J. Juvonen \& K. Wentzel (Eds.), Social Motivation: Understanding Children's School Adjustment (pp. 11-42). New York: Cambridge University Press.

Hughes, C. \& Dunn, J. (1998). Understanding mind and emotion: Longitudinal associations with mental-state talk between young friends. Developmental Psychology, 34 (5), 1026-1037.

Jenkins, J.M. \& Astington, J.W. (1996). Cognitive factors and family structure associated with theory of mind development in young children. Developmental Psychology, 32 (1), 70-78.

Lalonde, C.E. \& Chandler, M.J. (1995). False belief understanding goes to school: On the socialemotional consequences of coming early or late to a first theory of mind. Cognition and Emotion, 9 (2-3), 167-185. 
Lewis, C., Freeman, N.H., Kyriakidou, C., Maridaki-Kassoaki, K., \& Berridge, D.M. (1996). Social influence on false belief access: Specific sibling influences or general apprenticeship? Child Development, 67 (6), 2930-2947.

Lu, H., Su, Y., \& Wang, Q. (2008). Talking about others facilitates theory of mind in Chinese preschoolers. Developmental Psychology, 44 (6), 1726-1736.

Maccoby, E. (1990). Gender and relationships: A developmental account. American Psychologist, 45 (4), 513-520.

McCreary Centre Society. (2004). Healthy Youth Development: Highlights from the 2003 Adolescent Health Survey. Vancouver, British Columbia, Canada: Author.

Meins, E. (1997). Security of Attachment and the Social Development of Cognition. Hove: Psychology Press.

Piaget, J. (1945/1962) Play, Dreams and Imitation in Childhood. New York: Norton. (Original work published 1945).

Ricciardelli, L.A. \& McCabe, M.P. (2007). The muscular ideal: Psychological, social, and medical perspectives. In J. K. Thompson \& G. Cafri (Eds), Pursuit of Muscularity Among Adolescents (pp. 199-216). Washington, DC: American Psychological Association.

Ruffman, T., Slade, L., \& Crowe, E. (2002) The relation between children's and mothers' mental state language and theory-of-mind understanding. Child Development, 73 (3), 734-751.

Ruffman, T., Slade, L., Devitt, K., \& Crowe, E. (2006). What mothers say and what they do: The relation between parenting, theory of mind, language and conflict/cooperation. British fournal of Developmental Psychology, 24 (1), 105-124.

Slade, L. \& Ruffman, T. (2005). How language does (and does not) relate to theory of mind: A longitudinal study of syntax, semantics, working memory and false belief. British fournal of Developmental Psychology, 23 (1), 117-141.

Slomkowski, C. \& Dunn, J. (1996). Young children's understanding of other people's beliefs and feelings and their connected communication with friends. Developmental Psvchology, 32 (3), 442-447.

Saarni, C. (1984). An observational study of children's attempts to monitor their expressive behavior. Child Development, 55 (4), 1504-1513.

Symons, D.K. (2004). Mental state discourse, theory of mind, and the internalization of self-other understanding. Developmental Review, 24 (2), 159-188.

Taumoepeau, M. \& Ruffman, T. (2006). Mother and infant talk about mental states relates to desire language and emotion understanding. Child Development, 77 (2), 465-481.

Taumoepeau, M. \& Ruffman, T. (2008). Stepping stones to others' minds: Maternal talk relates to child mental state language and emotion understanding at 15 , 24 and 33 months. Child Development, 79 (2), 284-302.

Villanueva Badenes, L., Clemente Estevan, R.A., \& Garcia Bacete, F.J. (2000). Theory of mind and peer rejection at school. Social Development, 9(3), 271-283. 
Vygotsky, L.S. (1934/1987). Thinking and speech. In R.W. Rieber \& A.S. Carton (Eds.), The Collected Works of L.S. Vygotsky. Vol. 1 (pp. 37-285). New York: Plenum Press. (Original work published 1934).

Wellman, H.M. (2002). Understanding the psychological world: Developing a theory of mind. In U. Goswami (Ed.), Handbook of Childhood Cognitive Development (pp. 167-187). Oxford: Blackwell. 